\title{
Development of a questionnaire to measure perceived reasons for divorce seeking: an instrument development study
}

Mohammad Eslami ${ }^{1}$, Mahdieh Yazdanpanah ${ }^{2}$, Parnian Andalib ${ }^{3}$, Azardokht Rahimi ${ }^{3}$, Mansoureh Safizadeh ${ }^{4}$, Adeleh Dadvar ${ }^{5}$, Nouzar Nakhaee ${ }^{6}$

${ }^{1}$ Ph.D. of Health Education, Assistant Professor, Department of Population and Family Health, Ministry of Health and Medical Education, Tehran, Iran

${ }^{2}$ M.D., Expert on Reproductive Health, Department of Population and Family Health, Ministry of Health and Medical Education, Tehran, Iran

${ }^{3}$ M.Sc., Expert on Reproductive Health, Department of Population and Family Health, Ministry of Health and Medical Education, Tehran, Iran

${ }^{4}$ M.D. Expert on Reproductive Health, Department of Population and Family Health, Kerman University of Medical Sciences, Kerman, Iran

${ }^{5}$ M.Sc. Expert on Reproductive Health, Department of Population and Family Health, Kerman University of Medical Sciences, Kerman, Iran

${ }^{6}$ M.D. Professor, Neuroscience Research Center, Kerman University of Medical Sciences, Kerman, Iran

Type of article: Original

\begin{abstract}
Background: Subjective accounts of divorce seeking individuals is a useful complement to sociological and psychological causes of divorce at both individual and community level. Regarding the increasing trend of divorce worldwide, the need for a questionnaire measuring subjective reasons of divorce is felt more and more.

Objectives: The aim of this study was to develop and validate perceived causes of a divorce questionnaire in Iranian society.

Methods: This was an instrument development study that carried out in 2016, based on extensive literature reviews and interviews with individuals referring to "Family Intervention Centers to Reduce Divorce" in Kerman, Fars and Alborz provinces (Iran). At first, 38 items expressing the perceived reasons for divorce were extracted; then, 29 items were used in the questionnaire according to the experts' judgment. After that, the questionnaire was given to 570 participants. The structural validity was evaluated using two methods: exploratory factor analysis via principle axis factoring, and known group comparisons by paired-samples t-test. The internal consistency of the questionnaire was also examined by calculating the Cronbach's alpha and corrected item-total correlation. SPSS version 20 was used for statistical analysis.

Results: The mean age $( \pm$ SD) of women and men was $32.3( \pm 8.9)$ and $36.8( \pm 10.6)$, respectively. Based on an expert panel, content validity of 29 items was approved. Using principle axis factoring and varimax rotation, two components were extracted. These two factors were called "instrumental/external reasons" and "expressive and relationship-centered reasons." Factor loading of all 29 items was higher than 0.32. Cronbach's alpha of the two subscales was 0.84 and 0.85 , respectively. Corrected item-scale coefficient of all items was more than 0.2 .

Conclusions: According to the acceptable validity and reliability of the Perceived Reasons for Divorce Seeking Questionnaire, it can be used to ascertain people`s reasons for divorce seeking.

Keywords: Divorce, Questionnaire, Separation, Social problems
\end{abstract}

\section{Corresponding author:}

Professor Dr. Nouzar Nakhaee, Neuroscience Research Center, Kerman University of Medical Sciences, Kerman, Iran. Tel: +98.3433151937, Email: nakhaeen@kmu.ac.ir and nakhaeen@gmail.com

Received: September 11, 2017, Accepted: January 24, 2018, Published: July 2018

iThenticate screening: January 23, 2018, English editing: May 12, 2018, Quality control: May 14, 2018

This article has been reviewed / commented by five experts

Ethics approval: IR.KMU.REC1394.740

(C) 2018 The Authors. This is an open access article under the terms of the Creative Commons Attribution-NonCommercialNoDerivs License, which permits use and distribution in any medium, provided the original work is properly cited, the use is non-commercial and no modifications or adaptations are made. 


\section{Introduction}

Marriage is a part of life in almost all Western and Eastern culture (1). There are varied motives behind marriage including the need for social and emotional support, love and friendship and sexual relations (2). Divorce is considered a social issue when it exceeds the normal limit and becomes unconventional. In this regard, divorce is no longer a personal problem, but rather it is a multi-stage process that not only affects the way people interact in a family, but also causes severe harm to the community (3). Observing the circumstances of divorce is important not only from the aspects of its impact on the husband, wife and their children but also from the negative consequences on the whole society and economy such as the increased risk for major depression and poverty, and lower life expectancy (4). Divorce is one of the social harms which has significantly increased in most countries in recent decades (5). In recent years, the divorce trend and marriage instability have increased in Iran, which is currently considered one of the countries with high divorce rates (6). In 2011, the divorce rate in Iran was $2.5 \%$ per 1,000 in the age group of 15-64; it is even higher than the figure reported in some western countries including Ireland, Italy and Spain (6). Considering the increasing trend of divorce, paying attention to its causes is of particular importance (5). It is customary to ask the experts to understand the reasons and causes of these problems (5), and it is less likely to ask a layperson (7). There are three perspectives to determining divorce factors (7). In the sociological approach, phenomena such as individualism, modernization and life course predictors of divorce are discussed (7). In the psychological approach, variables such as personality traits, mental health and the quality of relationships between husbands and wives are considered (8). In the third approach, people are asked about the perceived causes of divorce (7). Amato and Previti stated that this research approach "provides a useful complement to more objective methods and is necessary for a full understanding of the divorce process." (7). Furthermore, in his well-known article, Slovic emphasized the layperson's viewpoint in planning to prevent community problems and stated, "their basic conceptualization of risk is much richer than that of the experts" (9). One of the strengths of using this method is that the reasons obtained from this kind of research are culturally appropriate (10). Moreover, planning to change the behavior of people "without understanding individuals' reason for engaging in the behavior, is condemned to failure" (11).

In Iran, few studies have been conducted on personal reasons of divorce, in which the questionnaires were researcher made with insufficient evidence of psychometric properties $(12,13)$. The most comprehensive study regarding people's reasons for divorce was done by Amato and Previti (7). In this study, they summarized the results of the related researches and concluded that infidelity was the most common reported reason for divorce (7). Despite introducing a comprehensive list of reasons in such studies, we found no study that had solely addressed a standard questionnaire regarding the issue. Although some research has been conducted in Iran on divorce etiology from the viewpoints of individuals facing divorce or those who are divorced, no questionnaire whose psychometric properties have been proved has been introduced in the literature, as far as it is concerned. The aim of this study was to create a questionnaire about the perceived reasons for divorce seeking in Iranian society, which, in addition to using indigenous studies, may also be informative for family scholars in other countries. To the best of our knowledge, this is the first study introducing a questionnaire measuring people`s reasons for request for divorce, specifically.

\section{Material and Methods}

\subsection{Instrument}

This was an instrument development study that carried out in 2016. At first, a questionnaire consisting of 38 questions was prepared based on the extensive literature review $(7,12-14)$ and interviews with couples seeking divorce and an expert panel focus group. The main source of item extraction was an Amato and Previti study (7) and a relevant study conducted in Tehran (13), and also the checklists and documents of the State Welfare Organization of Iran. After extraction of the first 38 items, we conducted face-to-face interviews with a subsample of 20 divorce volunteers to examine the comprehensibility and face validity of the items. The focus group consisted of five experts in divorce counseling. Their specialty was in community medicine, psychiatry, psychology, and counselling. The focus group discussion lasted 2 hours in one session. Then, the content validity of these questions was evaluated consensually, based on the judgment of the expert panel (15); the content validity and face validity of 29 questions was ultimately approved based on this qualitative method. It was named Perceived Reasons for Divorce Seeking Questionnaire (PRDSQ). Finally, these questions were given to 570 couples. They were enrolled in the study based on convenience sampling. Considering the subject to item ratio of 20 , sample size was calculated to be 580 for factor analysis of the 29 items of the questionnaire (16). In the introduction of the questionnaire, respondents were asked to specify the role and importance of each item statement in their marital dissolution using a five-point Likert scale. Responses included the following: 0: Not at all important, 1: Low importance, 2: Moderately important, 3: Very 
important, 4: Extremely important. So the questionnaire would display the most and/or the least important personal reasons for divorce.

\subsection{Setting}

This was a methodological study, carried out in 2016 using a cross sectional design. The subjects of this study were consecutively recruited from the centers of three provinces of Kerman, Fars and Alborz. These subjects included couples who had referred to family courts for divorce and then had been referred by the court to "Family Intervention Centers to Reduce Divorce" of which there are certified consultants. All of the referees were invited to participate in the study and the only exclusion criterion was unwillingness to complete the questionnaire. In these centers, the questionnaires were given separately to the husbands and wives; after explaining the questionnaires, the couples were asked to complete the questionnaires anonymously. In addition to providing counseling services, these centers attempt to bring the couples back to their normal lives and persuade them not to seek divorce. If the consent is obtained and the divorce is canceled, an arrangement letter is issued; otherwise, a divorce certificate is issued.

\subsection{Translation}

Since the original questionnaire was in Persian, to assure equivalence of the English translated version, the process of forward and backward translation was performed (16). The content and semantic equivalence of the translated version was established.

\subsection{Ethical considerations}

The protocol for this study was approved by the Ethics Committee of Kerman University of Medical Sciences (code: IR.KMU.REC1394.740). Before study enrollment, oral informed consent was obtained from potential participants. Confidentiality of the data was assured.

\subsection{Statistical analysis}

To analyze the construct validity of the PRDSQ, two methods were used: exploratory factor analysis (EFA) and known group comparisons (16). Correlation matrix of each pair of variables was checked prior to conducting factor analysis. Factorability was assessed via Bartlett's test of sphericity and Kaiser-Meyer-Olkin (KMO) statistic. For EFA, extraction was performed using principal axis factoring, and varimax rotation was used (17). The number of factors was determined using scree plot (17). The items with a loading factor of higher than 0.32 were kept in the questionnaire (17). To understand the local independency of the items, residual correlations were calculated (18). According to Amato and Previti, the perceived causes of divorce in women are expected to differ from men since emotional and relational issues are more important in women`s views (7). Thus, the mean scores of the two factors of the PRDSQ were compared between women and their husbands using the paired-samples t-test (16). Two methods were used to analyze the reliability. Primarily, Cronbach's alpha of the factors constituting the questionnaire was calculated. In addition, Cronbach's alpha if an item deleted, was also measured for each item. In the second method, the corrected item scale correlation was calculated for the items and a coefficient higher than 0.2 was considered as an indication that each item in the scale is adequately associated with the total score (16). Ceiling and floor effects for each subscale were calculated.

\section{Results}

In this study, 1,140 people consisting of 570 couples in three provinces were enrolled. The demographic characteristics of men and women referred to these centers are shown in Table 1. Mean \pm SD age male and female participants were $36.8 \pm 10.6$ and $32.3 \pm 8.9$ years, respectively. Both content and face validity of the 29 items were confirmed based on the opinions of experts and divorce seeking individuals, respectively. According to correlation matrix, there was no multicollinearity between the items (i.e., all coefficients were lower than \pm 0.90 . Kaiser-MeyerOlkin (KMO) measure of adequacy of samples was 0.922. P-value of the Bartlett's test of Sphericity was $<0.001$. Using principal axis factoring and varimax rotation, two factors were extracted (the loading factor of each item is shown in Table 2). Two factors were entitled "expressive and relationship-centered" and "instrumental/external" factors. They explained $34.4 \%$ of the variance $(27.5 \%$ and $7.9 \%$ for each factor, respectively). The scree plot (Figure 1) confirmed the two-factor nature of the questionnaire. According to the loading factor (Table 2), questions 1, 2, 4, $5,7-10,12,13,17,20-22,28$, and 29 were placed in the instrumental/external factor and the rest of the questions were placed in the expressive and relationship-centered factor. The residual correlation in all items was less than 0.1, indicating that the items were independent of one another and did not measure one thing. The results of the analysis of "Cronbach's alpha and corrected item-scale correlation" are shown in Table 2. Corrected item-scale correlation in all items was higher than 0.2. Cronbach's alpha of two "expressive and relationship-centered" and 
"instrumental/external" factors was 0.85 and 0.84 , respectively. Comparison of the scores of these two factors between men and women suggested that the score was significantly higher in women than in men (Table 3). Moreover, the expressive and relationship-centered score in both women and men was higher than that of the instrumental/external factor. There were no floor and ceiling effects. As a whole, $1.5 \%$ and $0.1 \%$ of participants achieved the lowest and the highest possible score, respectively.

Table 1. Demographic features of the subjects ( $n=570$ couples)

\begin{tabular}{|c|c|c|c|c|c|c|}
\hline \multicolumn{3}{|l|}{ Variable } & Mean & SD & $\mathrm{n}$ & $\%$ \\
\hline \multirow[t]{2}{*}{ Age (year) } & Women & & 32.3 & 8.9 & --- & --- \\
\hline & Men & & 36.8 & 10.6 & --- & --- \\
\hline \multicolumn{2}{|c|}{ Length of marriage (years) } & & 9.7 & 7.8 & --- & --- \\
\hline \multirow[t]{10}{*}{ Education level } & \multirow[t]{5}{*}{ Woman } & Illiterate & & & 3 & 0.5 \\
\hline & & Elementary & & & 40 & 7.0 \\
\hline & & Secondary school & & & 110 & 19.3 \\
\hline & & Diploma & & & 249 & 43.7 \\
\hline & & Academic & & & 168 & 29.5 \\
\hline & \multirow[t]{5}{*}{ Man } & Illiterate & & & 47 & 8.2 \\
\hline & & Elementary & & & 81 & 14.2 \\
\hline & & Secondary school & & & 122 & 21.4 \\
\hline & & Diploma & & & 209 & 36.7 \\
\hline & & Academic & & & 111 & 19.5 \\
\hline
\end{tabular}

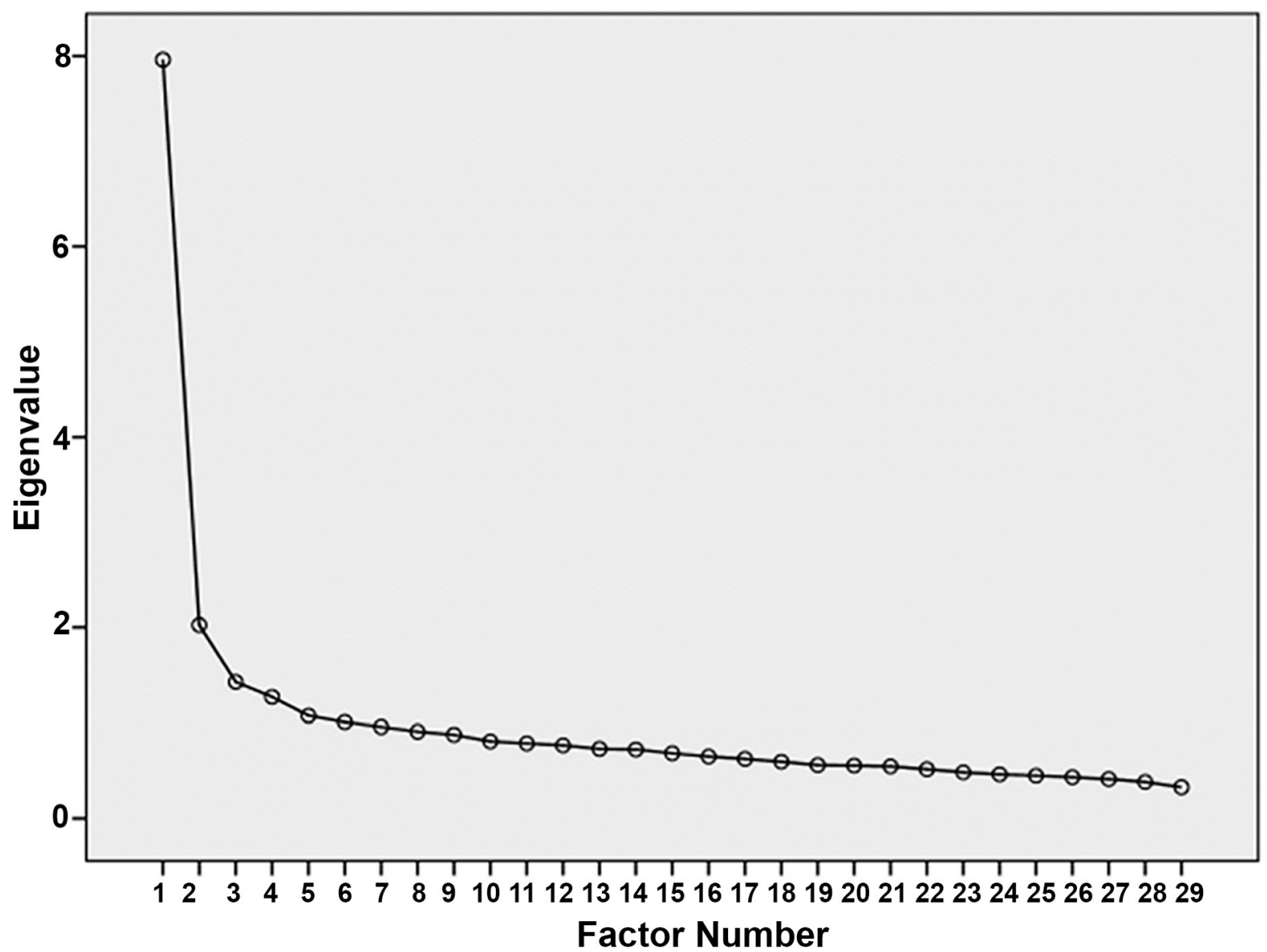

Figure 1. Scree plot 
Table 2. Factor loadings of each item and results of the reliability analysis

\begin{tabular}{|c|c|c|c|c|c|}
\hline \multirow[t]{2}{*}{ No. } & \multirow[t]{2}{*}{ Item } & \multicolumn{2}{|l|}{ Factor loadings } & \multirow{2}{*}{$\begin{array}{l}\text { Corrected } \\
\text { item-scale } \\
\text { correlation }\end{array}$} & \multirow{2}{*}{$\begin{array}{l}\text { Cronbach`s } \\
\text { alpha if item } \\
\text { deleted }\end{array}$} \\
\hline & & $\begin{array}{l}\text { Expressive and } \\
\text { relationship- } \\
\text { centered factor* }\end{array}$ & $\begin{array}{l}\text { Instrumental / } \\
\text { external factor* }\end{array}$ & & \\
\hline 1 & $\begin{array}{l}\text { I was forced to marry, and I was not interested in this } \\
\text { marriage from the beginning. }\end{array}$ & & 00.37 & 00.38 & 00.84 \\
\hline 2 & My spouse's addiction & & 00.48 & 00.51 & 00.83 \\
\hline 3 & My spouse's suspicion and pessimism & 00.43 & & 00.46 & 00.84 \\
\hline 4 & I came to the conclusion that my spouse betrayed me. & 00.32 & 00.34 & 00.42 & 00.84 \\
\hline 5 & Financial difficulties in providing life expenses & & 00.32 & 00.37 & 00.84 \\
\hline 6 & Problems with in-laws & 00.38 & & 00.39 & 00.84 \\
\hline 7 & High age difference with my spouse & & 00.50 & 00.45 & 00.83 \\
\hline 8 & Small age difference with my spouse & & 00.59 & 00.51 & 00.83 \\
\hline 9 & My spouse spends a lot of time with his friends & 00.35 & 00.42 & 00.50 & 00.83 \\
\hline 10 & The amount of Mahryeh (marriage payment) & & 00.51 & 00.46 & 00.83 \\
\hline 11 & Lack of sexual satisfaction and pleasure & 00.33 & & 00.39 & 00.84 \\
\hline 12 & Differences in religious beliefs & & 00.48 & 00.51 & 00.83 \\
\hline 13 & Infertility & & 00.59 & 0.46 & 00.83 \\
\hline 14 & My spouse's disrespect, contempt and insult, & 00.59 & & 00.58 & 00.83 \\
\hline 15 & My spouse beats me & 00.46 & 00.35 & 00.50 & 00.84 \\
\hline 16 & My spouse restricts my relationship with others & 00.50 & & 00.56 & 00.83 \\
\hline 17 & $\begin{array}{l}\text { My spouse doesn't agree with the nature of my } \\
\text { working out of the house }\end{array}$ & & & 00.36 & 00.84 \\
\hline 18 & Differences in raising our children & 00.38 & & 00.44 & 00.84 \\
\hline 19 & Differences in going to and having parties & 00.51 & & 00.54 & 00.84 \\
\hline 20 & Differences with my spouse's education level & & & 00.48 & 00.83 \\
\hline 21 & My spouse's physical illness & & & 00.58 & 00.83 \\
\hline 22 & My spouse's mental illness & 00.42 & & 00.50 & 00.83 \\
\hline 23 & My spouse interferes in other peoples' lives & 00.36 & & 00.44 & 00.84 \\
\hline 24 & My spouse is untrustworthy and untruthful & 00.60 & & 00.54 & 00.84 \\
\hline 25 & $\begin{array}{l}\text { Dissatisfaction with the way my spouse expresses his } \\
\text { love and feelings }\end{array}$ & 00.62 & & 00.57 & 00.83 \\
\hline 26 & Inability to resolve disputes that leads to a quarrel & 00.70 & & 00.57 & 00.83 \\
\hline 27 & Dissatisfaction with my spouse's personality traits & 00.64 & & 00.58 & 00.83 \\
\hline 28 & Prolonged period of engagement & & 00.40 & 00.43 & 00.84 \\
\hline 29 & The husband's unemployment & & 00.40 & 00.49 & 00.83 \\
\hline
\end{tabular}

* Loading factors greater than 0.32 were shown

Table 3. Comparison of the mean score of the two components of the PRDSQ* in men and women

\begin{tabular}{|l|l|l|l|}
\hline Component & Women & Men & Comparison of men and women \\
\hline Expressive and relationship-centered & $2.07 \pm 0.92$ & $1.70 \pm 0.99$ & $\mathrm{p}<0.001$ \\
\hline Instrumental/external & $1.20 \pm 0.78$ & $0.89 \pm 0.77$ & $\mathrm{p}<0.001$ \\
\hline Comparison of two subscales & $\mathrm{p}<0.001$ & $\mathrm{p}<0.001$ & \\
\hline
\end{tabular}

* Perceived Reasons for Divorce Seeking Questionnaire

\section{Discussion}

In order to understand the etiology of divorce, it is important to understand the perceived causes of couples seeking divorce (7). This study showed that PRDSQ had acceptable validity and reliability to assess the personal causes of divorce. The strength of this study was that it used an adequate number of samples in three different provinces of Iran. Most studies conducted on the issue of divorce are mainly based on the expert's viewpoints and have not focused on the perceived reasons of people (7). Moreover, most studies published in international journals on perceived causes of divorce have been carried out in Western countries (19). In Iran, a small number of studies conducted on this issue either have not provided sufficient evidence concerning their validity and reliability of their 
tools $(13,14)$, or have examined a specific subpopulation (12). Correlation matrix was in favor of patterned relationship amongst the items. The results of the KMO and Bartlett's tests indicated that the questionnaire was suitable for factor analysis and since the KMO number was greater than 0.9 , it was considered as an excellent measure of sampling adequacy (20). Two components were extracted, based on scree plot. Concerning the content of the questions and according to Amato and Previti categorization of personal causes of divorce, we named these two factors "instrumental/external" and "expressive and relationship-centered" reasons (7). The two broad-spectrum subjective causes of divorce in a US population were studied to be either related to external factors such as financial problems and emotional and relational issues such as spouse's emotional abuse and/or infidelity (7). In a study conducted on divorce seeking women in Iran, four domains were explored based on factor analysis, in which three factors were related to the husband's issues (social abnormalities, lack of social skills and wife neglect) and the fourth factor was related to the spouse's family mismatches (12). In this study, most items focused on husband problems which may be due to the fact that all participants were women. In our study, we tried to enroll both couples to avoid any gender related bias when exploring the subjective reasons for divorce.

The loading factor of all 29 questions was above the acceptable level of 0.32 (17). None of the items had a residual correlation of higher than 0.1 , indicating that the items were not similar and had no overlap, and every item asked about a separate and different issue (18). The amount of explained variance in our study was lower than the recommended value of $50 \%$ (20), which may be due to extraction of only two factors. Since "retaining too many factors can deplete the solution erroneously resulting in weak factor loadings" (20) and based on conceptual examination of the items, we preferred to emphasize on the two-factor solution. In the Iranian study on divorce factors among women, the proposed questionnaire, which consisted of 145 items, yielded four factors accounting for $41 \%$ of total variance (12). The score of the PRDSQ was greater in women that in men (in both subscales), in other words, women had more credence to both emotional and external factors compared to men. It has been well documented that women, more often than men, blame the divorce on relational and emotional factors such as general lack of love (7). Moreover, the relationship-centered reasons were taken into more consideration than the instrumental/external reasons, which is in line with the findings of relevant studies (7). The statistical difference between the views of men and women in both domains of the questionnaire (7) met the predefined expectations, and thus the known group validity of the questionnaire was confirmed (16). Cronbach's alpha of the two components of the questionnaire (both above the minimum acceptable level of 0.7) showed good internal consistency of the questionnaire. Corrected item-scale correlation in all items was higher than the minimum acceptable of 0.2 , which was another reason for the reliability of the questionnaire (16). Both ceiling and floor effects were acceptable, which is in favor of content validity (21). The PRDSQ Cronbach`s alpha was higher than other Iranian questionnaires. In a study conducted on divorce seeking couples referring to Tehran Family Courts, the Cronbach's alpha of the questionnaire was 0.7 (13) and the corresponding figure in another Iranian study was 0.6 (12). Nunnally suggested that at least two criteria should be used to assess the psychometric properties of the questionnaire in measuring both the validity and the reliability (22). Although confirmatory factor analysis was not checked, the validity of the questionnaire was calculated using three ways of content validity, factorial validity and known group validity, and reliability was measured through Cronbach's alpha and corrected item-scale correlation. The study had two limitations. First, it was preferable to use a more representative sample from all regions of the country. Second, to find out the number of factors, more objective methods rather than scree plot may be used.

\section{Conclusions}

In short, the findings showed that the psychometric properties of this questionnaire were acceptable for measuring the perceived causes of divorce seeking in Iranian society. The implication of the study is that it provides a framework for researchers and family counselors to explore the subjective and personal reasons for marital dissolution via a valid and reliable tool. Awareness of counsellors about perceived reasons for divorce seeking in referees to courts and counselling centers would improve the plans for early interventions to solve marital conflicts. To further confirm the construct validity of the PRDSQ it warrants future research using confirmatory factor analysis.

\section{Acknowledgments:}

We would like to thank the State Welfare Organization of Iran for facilitating the data gathering process. We also thank the Department of Population and Family Health, and the Ministry of Health and Medical Education for financial support. 


\section{Conflict of Interest:}

There is no conflict of interest to be declared.

\section{Authors' contributions:}

All authors contributed to this project and article equally. All authors read and approved the final manuscript.

\section{References:}

1) Myers JE, Madathil J, Tingle LR. Marriage satisfaction and wellness in India and the United States: a preliminary comparison of arranged marriages and marriages of choice. J Counsel Develop. 2005; 83: 183 90. doi: 10.1002/j.1556-6678.2005.tb00595.x.

2) Waite LJ, Lehrer ER. The benefits from marriage and religion in the United States: a comparative analysis Popul Dev Rev. 2003; 29(2): 255-76. doi: 10.1111/j.1728-4457.2003.00255.x. PMID: 19129930, PMCID: PMC2614329.

3) Amato PR. Research on divorce: Continuing trends and new developments. J Marriage Fam. 2010; 72(3): 650-66. doi: 10.1111/j.1741-3737.2010.00723.x.

4) Härkönen J. Divorce: Trends, Patterns, Causes, and Consequences. In: The Wiley-Blackwell companion to the sociology of families. John Wiley \& Sons; 2014: 303-22.

5) Safizadeh M, Nakhaee N. Causes of increasing trend of divorce in Iranian community: what do the experts think? J Fam Med. 2016; 3(4): 1064.

6) Aghajanian A, Thompson V. Recent divorce trend in Iran. J Divorce Remarriage 2013; 54(2): 112-25. doi: 10.1080/10502556.2012.752687.

7) Amato PR, Previti D. People's reasons for divorcing: Gender, social class, the life course, and adjustment. J Fam Issues. 2003; 24(5): 602-26. doi: 10.1177/0192513X03024005002.

8) Mojtabai R, Stuart EA, Hwang I, Eaton WW, Sampson N, Kessler RC. Long-term effects of mental disorders on marital outcomes in the National Comorbidity Survey ten-year follow-up. Soc Psychiatry Psychiatr Epidemiol. 2017; 52(10): 1217-26. doi: 10.1007/s00127-017-1373-1. PMID: 28378065.

9) Slovic P. Perception of Risk. Science. 1987; 236: 280-5. doi: 10.1126/science.3563507.

10) Castro FG, Barrera M, Martinez CR. The cultural adaptation of prevention interventions: resolving tensions between fidelity and fit. Prev Sci. 2004; 5(1): 41-5. doi: 10.1023/B:PREV.0000013980.12412.cd. PMID: 15058911.

11) Nakhaee N, Jadidi N. Why do some teens turn to drugs? a focus group study of drug users' experiences. J Addict Nursing. 2009; 20(4): 203-8. doi: 10.3109/10884600903291158.

12) Khojastehmehr R, Takrimi A. Identification of divorce factors of women. Journal of Applied Sciences. 2009; 9(20): 3758-63. doi: 10.3923/jas.2009.3758.3763.

13) Honarian M, Younesi SJ. Investigating the causes of divorce in the family courts in Tehran. Journal of Clinical Psychology. 2011; 1(3): 127-35.

14) Barikani A, Ebrahim SM, Navid M. The cause of divorce among men and women referred to marriage and legal office in Qazvin, Iran. Glob J Health Sci. 2012; 4(5): 184-91. doi: 10.5539/gjhs.v4n5p184. PMID: 22980391.

15) Abramson J, Abramson ZH. Research methods in community medicine: surveys, epidemiological research, programme evaluation, clinical trials. John Wiley \& Sons; 2011.

16) Nakhaee N. Questionnaire design \& analysis. 1st ed. Kerman: Gera Publications; 2013.

17) Osborne JW, Costello AB. Best practices in exploratory factor analysis: Four recommendations for getting the most from your analysis. Pan-Pacific Management Review. 2009; 12(2): 131-46.

18) McDonald RP. Test theory: A unified treatment. Psychology Press; 2013.

19) Scott SB, Rhoades GK, Stanley SM, Allen ES, Markman HJ. Reasons for divorce and recollections of premarital intervention: Implications for improving relationship education. Couple Family Psychol. 2013; 2(2): 131-45. doi: 10.1037/a0032025. PMID: 24818068.

20) Beavers AS, Lounsbury JW, Richards JK, Huck SW, Skolits GJ, Esquivel SL. Practical considerations for using exploratory factor analysis in educational research. Practical assessment, research \& evaluation. $2013 ; 18(6)$.

21) Terwee CB, Bot SD, de Boer MR, van der Windt DA, Knol DL, Dekker J, et al. Quality criteria were proposed for measurement properties of health status questionnaires. Journal of clinical epidemiology. 2007; 60(1): 34-42. doi: 10.1016/j.jclinepi.2006.03.012. PMID: 17161752.

22) Nunnally JC, Bernstein IH. Psychometric theory. 3rd ed. New York: McGraw-Hill; 1994. 